\title{
ANÁLISE DA EFICIÊNCIA DO TIJOLO ECOLÓGICO SOLO-CIMENTO NA
}

\author{
CONSTRUÇÃO CIVIL
}

ANALYSIS OF THE EFFICIENCY OF ECOLOGICAL BRICK SOLO-CEMENT IN CIVIL

CONSTRUCTION

Eduardo Weber $^{1}$
Roger Francisco Ferreira de Campos
Tiago Borga

\section{RESUMO}

Vem se destacando entre os principais materiais inovadores da construção civil o tijolo reciclado, ou ecológico, que desfruta das técnicas de fabricação solo-cimento normalizadas pela ABNT. Diante do exposto esse trabalho tem como objetivo realizar um breve levantamento bibliográfico sobre a eficiência da utilização de tijolos ecológicos na construção civil, com ênfase em práticas socioeconômicas visando à sustentabilidade. O produto pode ser utilizado tanto em alvenaria estrutural como em alvenaria de vedação, proporcionando benefícios em ambas as situações. 0 método construtivo que o tijolo solo-cimento permite utilizar resulta em vantagens técnicas, econômicas e ambientais. Por se tratar de um elemento construtivo caracterizado como ecológico, no Brasil, ainda, se faz necessário uma quebra de paradigmas de que um produto reciclado ou ecologicamente correto é ineficiente, para isto, se faz necessário disponibilizar informações técnicas mostrando o contrário.

Palavras-Chave: Solo-cimento. Ecológico. Alvenaria.

1 Engenheiro Civil pela Universidade Alto Vale do Rio do Peixe - UNIARP, e-mail: eduardovbr2@gmail.com.

2 Engenheiro Ambiental, Especialista em Engenharia Ambiental e Sanitária, Mestrando em Ciências Ambientais pela Universidade Estadual de Santa Catarina - UDESC/CAV. Professor do curso de Engenharia Ambiental e Sanitária da Universidade Alto Vale do Rio do Peixe - UNIARP e-mail: roger@uniarp.edu.br.

3 Engenheiro Ambiental, Especialista em Gestão, Perícia e Auditoria Ambiental, Mestrando em Desenvolvimento e Sociedade pela da Universidade Alto Vale do Rio do Peixe - UNIARP. Professor do curso de Engenharia Ambiental e Sanitária da Universidade Alto Vale do Rio do Peixe - UNIARP. email: tiagoborga@gmail.com. 


\section{ABSTRACT}

Among the main innovative building materials is the recycled brick, or ecological, that enjoys the techniques of manufacturing soil-cement standardized by ABNT. In view of the above, this work aims to carry out a brief bibliographic survey on the efficiency of the use of ecological bricks in civil construction, with emphasis on socioeconomic practices aiming at sustainability. The product can be used both in structural masonry and in masonry sealing, providing benefits in both situations. The constructive method that brick soil-cement allows to use results in technical, economic and environmental advantages. Because it is a constructive element characterized as ecological, in Brazil, it is still necessary to break paradigms that a recycled or ecologically correct product is inefficient, for this, it is necessary to make available technical information showing the opposite.

Keywords: Soil-cement. Ecological. Masonry.

\section{INTRODUÇÃO}

O termo sustentabilidade é sem dúvida um dos mais comentados neste novo milênio, esse conceito está entrelaçado nas mais diversas áreas de planejamento e setores da economia (BRAGA et al., 2010). Na construção civil, com a utilização de materiais inovadores capazes de gerar o menor impacto possível ao meio ambiente e que estimulem o conforto térmico ou a redução do consumo de energia, não é diferente, e a diversidade de novos materiais e tecnologias com essa finalidade é imensurável (YEMAL; TEIXEIRA; NÃÃS, 2011).

Vem se destacando entre os principais materiais inovadores da construção civil o tijolo reciclado, ou ecológico, que desfruta das técnicas de fabricação solocimento normalizadas pela ABNT, trazendo diversos benefícios para obras de pequeno e médio porte. O produto pode ser de caráter estrutural ou não, passando por ensaios destrutivos que garantem a sua resistência resultada das proporções e dimensões definidas na fabricação. Disponibiliza de uma gama de possibilidades de acabamentos que ficam a critério do cliente escolher, proporcionando satisfação e conforto ao mesmo (GODOI, 2012).

Esta aplicação do Tijolo Ecológico, além de contribuir para o meio ambiente por evitar a emissão de gases de efeito estufa no seu processo de fabricação, contribuirá maciçamente na economia do país, tendo em vista o reaproveitamento de materiais vegetais descartáveis, pois é um produto que possui as características 
de ser durável e resistente, além de baixo custo e alto potencial de aplicabilidade na construção civil no que se refere à construção de moradias populares (SANTOS; SUZART; SILVA-JUNIOR, 2013).

A quantidade de material (resíduos) deixado pelo processo das construções civil torna-se dia a dia um dos problemas a serem enfrentados e que nos põem a pensar em atitudes e técnicas para que possamos reduzir esse volume de alguma forma. Em um olhar econômico verifica-se que ocorrem grandes reduções nos custos da produção do tijolo tendo em vista que a principal matéria prima é de baixo valor e os demais componentes são simples e de fácil acesso. O processo de transformação desta matéria para produto final pode ser manual ou automatizado, necessitando apenas pressão sobre o molde com as medidas normatizadas do tijolo ecológico. Sendo assim o preço se torna mais acessível tanto para produção quanto para venda ao consumidor final.

Os resíduos que são provenientes dos rejeitos da construção civil, embora não apresente um incomodo, mas sob o ponto de vista da toxidade, assusta pelo seu volume crescente e requerendo medidas imediatas (COELHO; CHAVE, 1998). Além de ser a atividade econômica que mais consome recursos naturais, é também a maior geradora de resíduos urbanos. É possível identificar que na história da humanidade o solo é utilizado em construções das mais variadas dimensões, desde que trabalhado através de técnicas de preparação que proporcionam um aproveitamento total de sua resistência. Com isto, não há dúvidas de que um elemento construtivo feito a partir do solo, estabilizado com outras matérias primas, resultará em um elemento resistente e de qualidade.

Contudo devemos notar que ao aplicar esses recursos em construções, o engenheiro ou construtora que está responsável pela obra seja consciente e financeiramente estável. Visto que possui a responsabilidade com a condição ambientais da obra e indiretamente sobre a forma que o planeta se encontra, alinhado com as necessidades do consumidor. Diante de contexto o presente trabalho tem como objetivo analisar a eficiência da utilização de tijolos ecológicos na construção civil, com ênfase em práticas socioeconômicas visando à sustentabilidade. 


\section{MATERIAIS E MÉTODOS}

Para o desenvolvimento do presente trabalho foram analisados dados já concluídos através de pesquisas bibliográficas, sendo eles: características do tijolo ecológico tais como: aparência, conforto, aplicações e tipos de acabamento, aplicações do tijolo em construções de pequeno e médio porte, comparação de custo e qualidade em relação aos tijolos de adobe e cerâmica. A pesquisa possui natureza descritiva. Segundo Gil (2007, p.42) "as pesquisas descritivas têm como objetivo primordial a descrição das características de determinada população ou fenômeno ou, então, o estabelecimento de relações entre variáveis"

\section{RESULTADOS E DISCUSSÕES}

\section{MERCADO DE TIJOLO ECOLÓGICO}

O mercado de materiais para construção civil está em constante mudança devido a novas tecnologias e aperfeiçoamentos de materiais construtivos, com isso, o preço dos diferentes tipos de tijolos varia de acordo com as suas características, fabricante e fornecedor. Visando relacionar os custos de alguns tijolos que podem ser aplicados na construção de paredes, baseando-se na média de preços pesquisada em sites de lojas de materiais para construção (Tabela 1.).

Tabela 1. Tabela de custos dos tijolos;

\begin{tabular}{lccc}
\hline & $\begin{array}{l}\text { Tijolo de solo-cimento } \\
(25 \times 12,5 \times 6,5 \mathrm{~cm})\end{array}$ & $\begin{array}{l}\text { Tijolo 6 furos cerâmico } \\
(9 \times 14 \times 19 \mathrm{~cm})\end{array}$ & $\begin{array}{l}\text { Bloco estrutural } \\
(9 \times 19 \times 29 \mathrm{~cm})\end{array}$ \\
\hline Quantidade por $\mathrm{m}^{2}$ & 55 & 37 & 13,5 \\
Custo por unidade* & $\mathrm{R} \$ 1,05$ & $\mathrm{R} \$ 0,40$ & $\mathrm{R} \$ 1,45$ \\
Custo por $\mathrm{m}^{2}$ & $\mathrm{R} \$ 57,75$ & $\mathrm{R} \$ 14,80$ & $\mathrm{R} \$ 19,58$ \\
\hline
\end{tabular}

$(*)$ Valores obtido no comercio de Santa Catarina.

Analisa-se que comprar o tijolo ecológico sem uma análise prévia na elaboração do projeto considerando todas as etapas da obra e os demais materiais necessários, não se mostra uma boa opção de economia. 
Atualmente o valor da unidade do tijolo ecológico no mercado está na média de preços de blocos estruturais, o que muitas vezes deixa de ser uma opção do cliente devido aos paradigmas de que material sustentável é mais frágil, ou possui menor vida útil. Um orçamento completo de execução de obra pode vir a mostrar a verdadeira economia do tijolo ecológico, que se dá no processo de utilização do mesmo, tempo de execução, praticidade, economia de materiais, eficiência energética, dentre outras inúmeras vantagens.

Com um orçamento de todas as etapas do cronograma de execução da obra, pode-se dizer que o tijolo ecológico é uma ótima opção para economia na execução de projetos de pequeno e médio porte. A melhor forma de economia utilizando tijolo ecológico é a possibilidade da fabricação do mesmo in loco.

O custo do tijolo diminui da média de $R \$ 1,05$ para $R \$ 0,25$, desde que 0 proprietário ou empreiteira/construtora que irá executar a obra disponha do equipamento que será um molde no valor de duzentos e cinquenta reais, e uma prensa manual ou hidráulica que custam em média, respectivamente, mil reais e dois mil e quinhentos reais, um ótimo investimento para quem trabalha com o tijolo.

O tijolo ecológico possui uma particularidade de acabamento por se tratar de um tijolo composto através de solo-cimento, resulta em coloração diferenciada aos tijolos tradicionais ou cerâmicos. Adapta-se em ambientes rurais ou urbanos com facilidade, bastando apenas combinar componentes da habitação como esquadrias, telhados, chaminés, calçadas, entre outros. Por ser um material que aceita diversos tipos de acabamento além do seu próprio corpo a vista apenas envernizado, arquitetos optam pelo produto devido a facilidade na execução de seus projetos.

Dispondo-se de três modelos de tijolo ecológico, para evitar a geração de resíduos de recortes na obra, deve-se quantificar cada tipo de tijolo que será utilizado. Dentre eles destaca-se o modular com $25 \times 12,5 \times 7 \mathrm{~cm}$ e rendimento de 57 peças por metro quadrado; o meio com $12,5 \times 12,5 \times 7 \mathrm{~cm}$, que deverá ser adquirido aproximadamente $5 \%$ da quantidade de modulares, e o canaleta, conforme mostra a figura 12 , utilizado para execução de vergas, contravergas e vigas; ambas com dimensões de $25 \times 12,5 \times 7 \mathrm{~cm}$.

O tijolo ecológico se destaca juntamente com o tijolo de adobe pelo seu processo de fabricação considerado limpo, por não necessitar da queima de lenha 
para aquecimento de fornos para secagem, evitando emissão de gases de efeito estufa. Diferente do tijolo de adobe, o ecológico necessita de prensa manual ou hidráulica com capacidade de seis toneladas de pressão e molde confeccionado em aço com as dimensões padronizadas do tijolo para sua fabricação.

Por se tratar de um tijolo que ainda não possui normas técnicas que designam medidas padronizadas, o molde do tijolo de adobe é confeccionado com madeira e permite a realização da forma necessária para a construção, e o processo de confecção varia muito de uma região para outra, pois se originou no Brasil a partir das colonizações. O tijolo ecológico é regido pelas normas técnicas da ABNT que determinam o traço da mistura de solo-cimento para confecção, pressão mínima para compactação, medidas dos tijolos para assim serem classificados entre bloco estrutural ou de vedação, dentre outras.

Para realizar o dimensionamento de estruturas de concreto armado precisamos determinar cargas que atuarão sobre componentes estruturais, dentre estas atuam o peso das paredes, o peso próprio se dá pelo somatório do peso do tijolo e revestimentos. A seguir segue um comparativo entre os pesos dos tijolos desenvolvida através de dados de dois fornecedores de tijolos das cidades de Jaguaruna/SC e São Paulo/SP conforme suas características, (Tabela 2.).

Tabela 2. Comparativo de pesos

\begin{tabular}{lcccc}
\hline Produto* & $\begin{array}{l}\text { Dimensões } \\
(\mathrm{cm})\end{array}$ & $\begin{array}{l}\text { Peso } \\
(\mathrm{Kg})\end{array}$ & $\begin{array}{l}\text { Peças por } \\
\mathrm{m}^{2} \\
\text { (Peças) }\end{array}$ & $\begin{array}{l}\text { Peso por } \mathrm{m}^{2} \\
(\mathrm{Kg})\end{array}$ \\
\hline Tijolo modular solo-cimento & $12,5 \times 25 \times 6,25$ & 2,750 & 64 & 176,000 \\
Meio tijolo modular solo-cimento & $12,5 \times 12,5 \times 6,25$ & 1,375 & 128 & 176,000 \\
Canaleta modular solo-cimento & $12,5 \times 25 \times 6,25$ & 1,900 & 64 & 121,600 \\
Tijolo modular solo-cimento & $15 \times 30 \times 7,5$ & 4,300 & 45 & 193,500 \\
Meio tijolo modular solo-cimento & $15 \times 15 \times 7,5$ & 2,150 & 90 & 193,500 \\
Canaleta modular solo-cimento & $15 \times 30 \times 7,5$ & 3,100 & 45 & 139,500 \\
Tijolo cerâmico 6 furos & $9 \times 24 \times 14$ & 2,210 & 40 & 88,400 \\
Tijolo cerâmico 8 furos & $9 \times 19 \times 19$ & 2,450 & 50 & 122,500 \\
Tijolo cerâmico 12 furos & $14 \times 29 \times 19$ & 5,350 & 22 & 117,700 \\
Canaleta cerâmica & $11,5 \times 19 \times 9$ & 1,450 & 56 & 81,200
\end{tabular}




\begin{tabular}{lllll}
\hline Canaleta cerâmica & $14 \times 19 \times 9$ & 1,700 & 56 & 95,200 \\
\hline
\end{tabular}

Considerando a tabela acima, pode-se fazer uma relação de peso específico entre o tijolo cerâmico e o solo-cimento, assim mostrando que o tijolo de solocimento possui um peso maior em relação ao cerâmico, podendo resultar de $40 \%$ a $50 \%$ do peso da cerâmica. Quando utilizado sem função estrutural, somente como alvenaria de vedação, resultará em uma carga de peso próprio maior que a do tijolo cerâmico sobre as vigas de apoio, consequentemente maior será o consumo de aço e concreto na estrutura.

\section{APLICAÇÃO DO TIJOLO SOLO-CIMENTO EM ALVENARIA}

Primeiramente deve-se quantificar cada tipo de tijolo que será utilizado na obra. Dentre eles temos: o modular com $25 \times 12,5 \times 7 \mathrm{~cm}$ e rendimento de 57 peças por metro quadrado; o meio com $12,5 \times 12,5 \times 7 \mathrm{~cm}$, que deverá ser adquirido aproximadamente $5 \%$ da quantidade de modulares, e o canaleta utilizado para execução de vergas, contravergas e vigas; ambas com dimensões de $25 \times 12,5 \times 7$ $\mathrm{cm}$.

Deve-se limitar em 4 ou 5 metros o comprimento das paredes a serem construídas com o tijolo solo-cimento, com o objetivo de diminuir a retração dos tijolos propícios ao surgimento de patologias. Caso haja a necessidade da construção de paredes extensas é aconselhável a utilização de juntas de dilatação, deixando entre um tijolo e outro dois milimetros de distância.

Com o projeto arquitetônico em mãos, inicia-se o processo de execução, onde é realizado um contra piso nivelado e em seguida impermeabilizado a região onde se encontrará a alvenaria, conforme figura abaixo: 


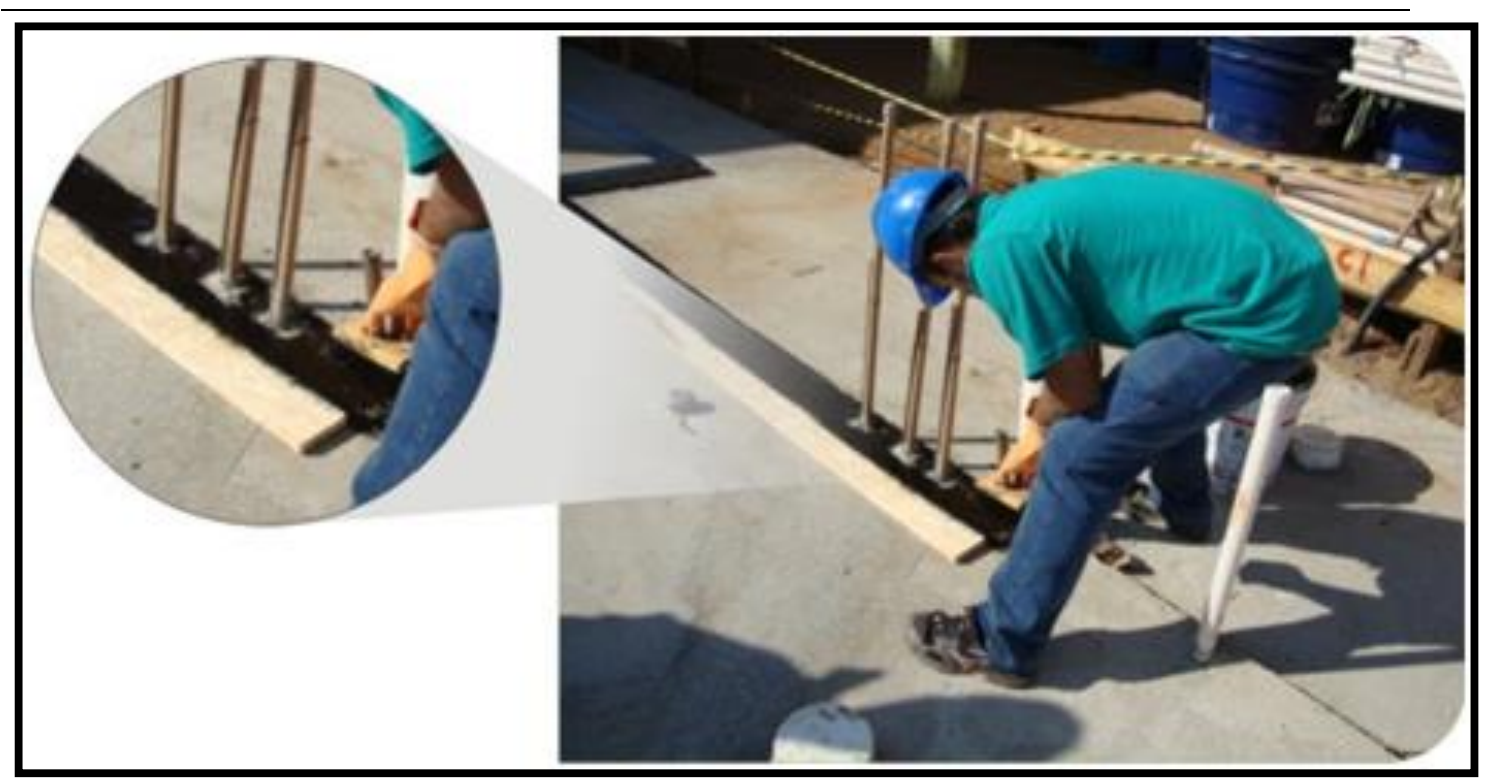

Figura 1. Impermeabilização

Fonte: Intijol. (2015)

Práticas como molhar os tijolos antes o assentamento não são aconselhadas, caso os tijolos apresentarem aparência de secos, umidecer superficialmente, sem saturá-lo. A argamassa utilizada no assentamento pode ser constituída também de solo, porém alguns cuidados especiais se fazem necessários.

Obrigatoriamente a mistura deve ser coesa e plástica, proporcionando facilidade na aplicação. Dois tipos de traço podem ser utilizados, um composto por cimento e solo, sendo 1:14, e o outro por cimento, cal e solo, na proporção 1:3:12. Testes já executados por empresas que realizam obras com este tipo de argamassa mostram que a resistência fica igual, até mesmo superior a do tijolo solo-cimento.

Com o assentamento dos tijolos da primeira fiada concluído, colocam-se as barras de aço para o graute, realizando furos na fundação em todos os cantos de paredes, nas uniões em " $T$ ", laterais de portas e janelas e a cada 75 centímetros de parede. 


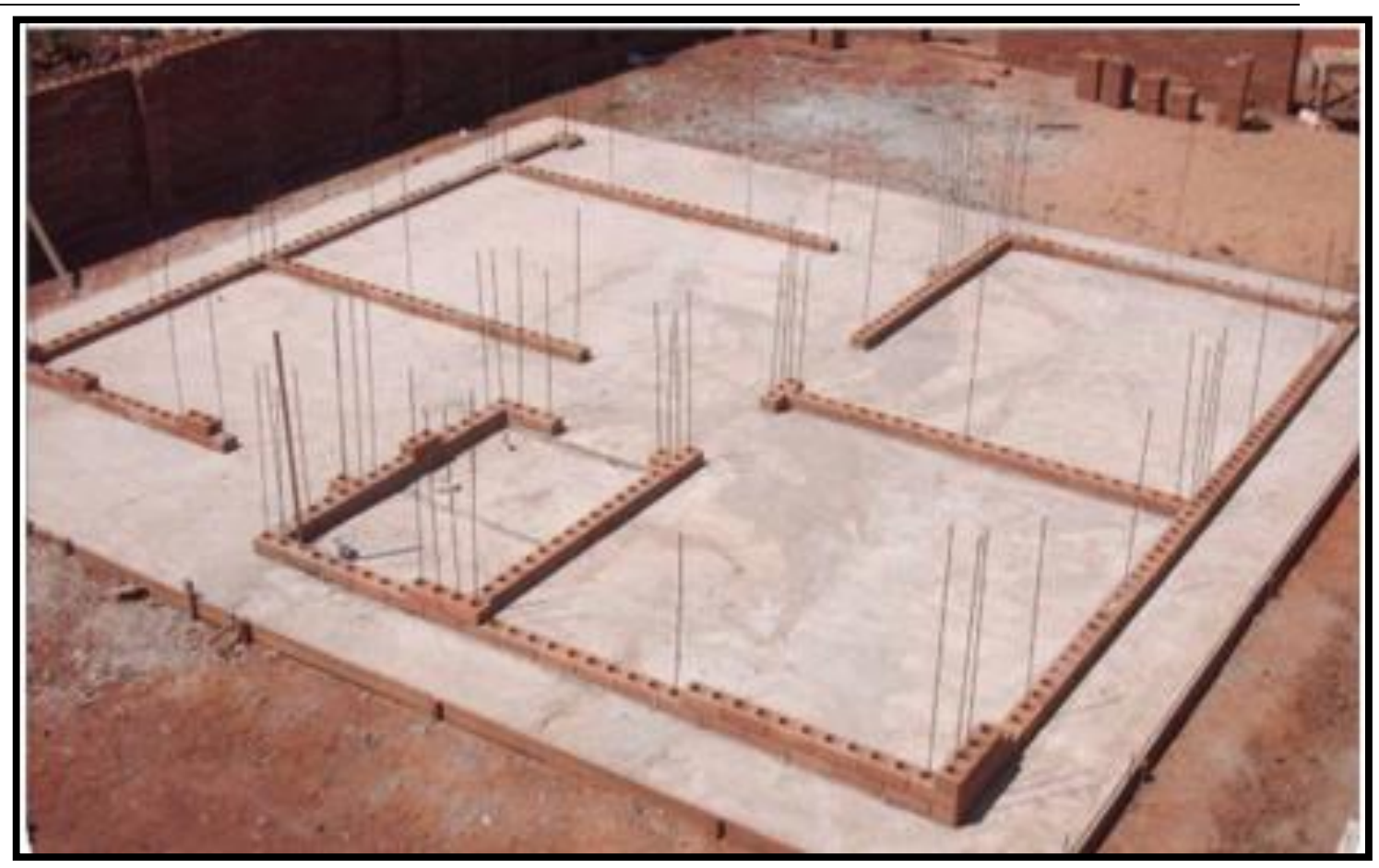

Figura 2. Aços embutidos na fundação

Fonte: Intijol. (2015)

Durante a concretagem dos pilaretes, deve-se assegurar que não fiquem vazios ao longo dos mesmos. Para isto, o lançamento do graute é feito em etapas.

Na parte inferior da janela é feita a primeira cinta de amarração com os tijolos tipo canaletas. Na parte superior das janelas e portas faz-se a segunda cinta para fechar os vãos, criando assim vergas e contra vergas com o objetivo de evitar patologias em pontos mais propícios. Dependendo do projeto, uma terceira cinta é realizada na última fiada. Estas cintas de amarração devem ser realizadas em todas as paredes independente se há ou não portas e janelas. 


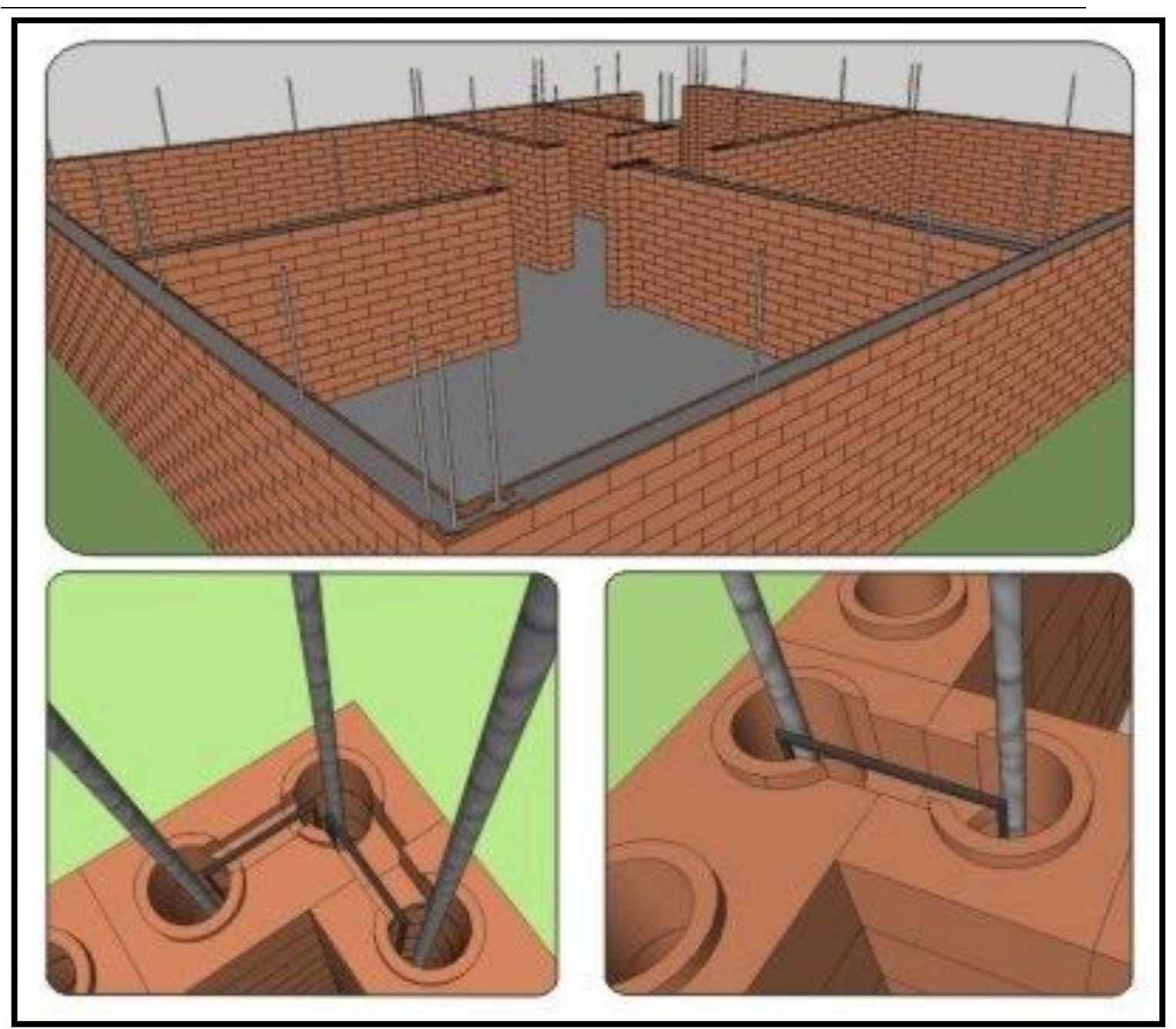

Figura 3. Cintas e amarrações

Fonte: Intijol. (2015)

Após a execução das paredes e o telhado, inicia-se a etapa de acabamento. Nas paredes que forem ficar a vista os tijolos, deve-se verificar a existência de algum tijolo danificado, se necessário substituir a face do mesmo para assim aplicar duas d'mãos de resina acrílica e em seguida realizar o rejunte dos tijolos. 


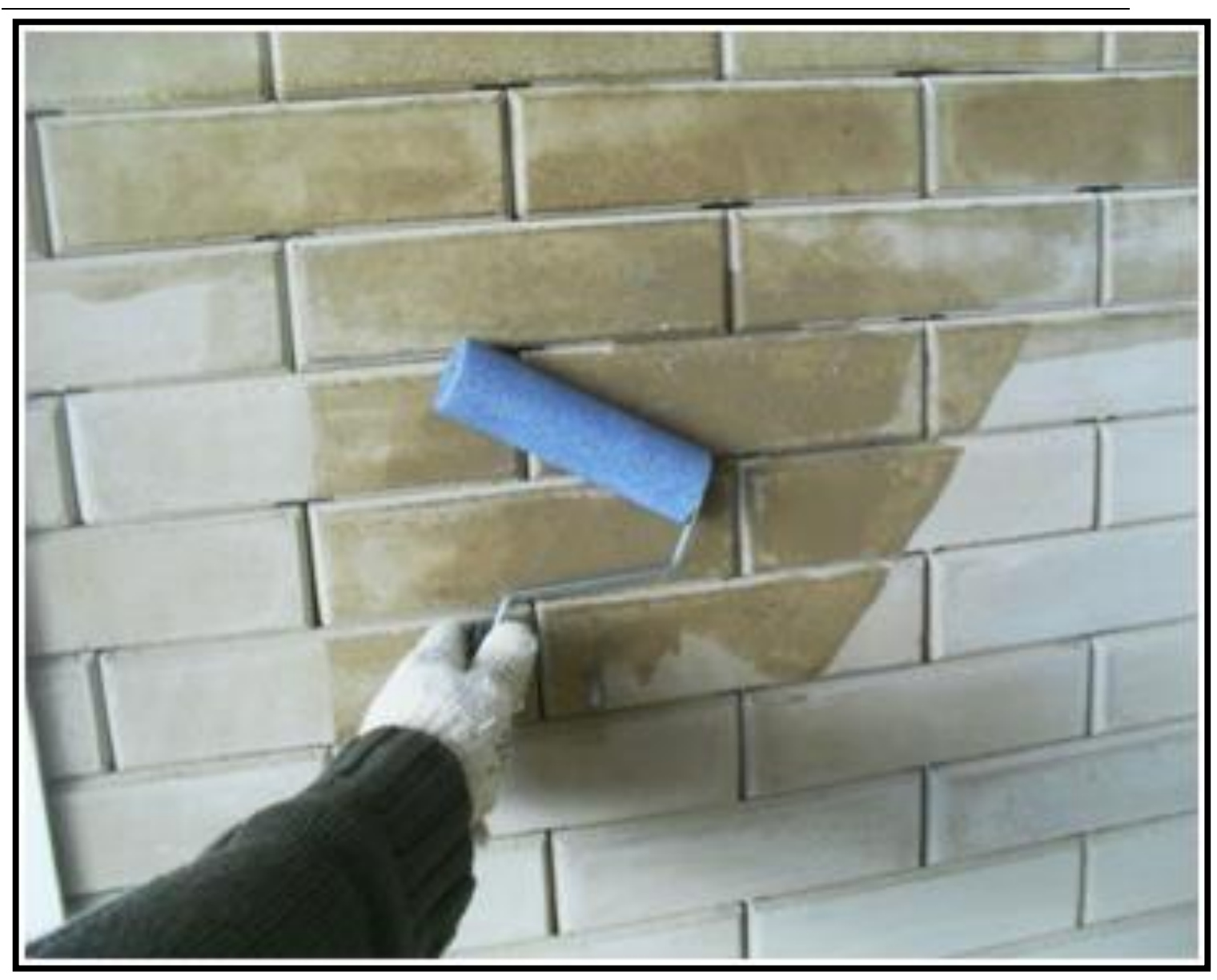

Figura 4. Aplicação de resina

Fonte: Intijol. (2015)

Em paredes, principalmente internas, onde não ficará o tijolo aparente por opção de acabamento diferenciado como o gesso, reboco e pintura, assentamento de cerâmica, dentre outros, não há a necessidade de realizar o rejunte. Em função da umidade do meio, o solo-cimento possui uma tendência a retração hidráulica, a qual deve ser amenizada com o revestimento das paredes de áreas molháveis e externas da edificação. 


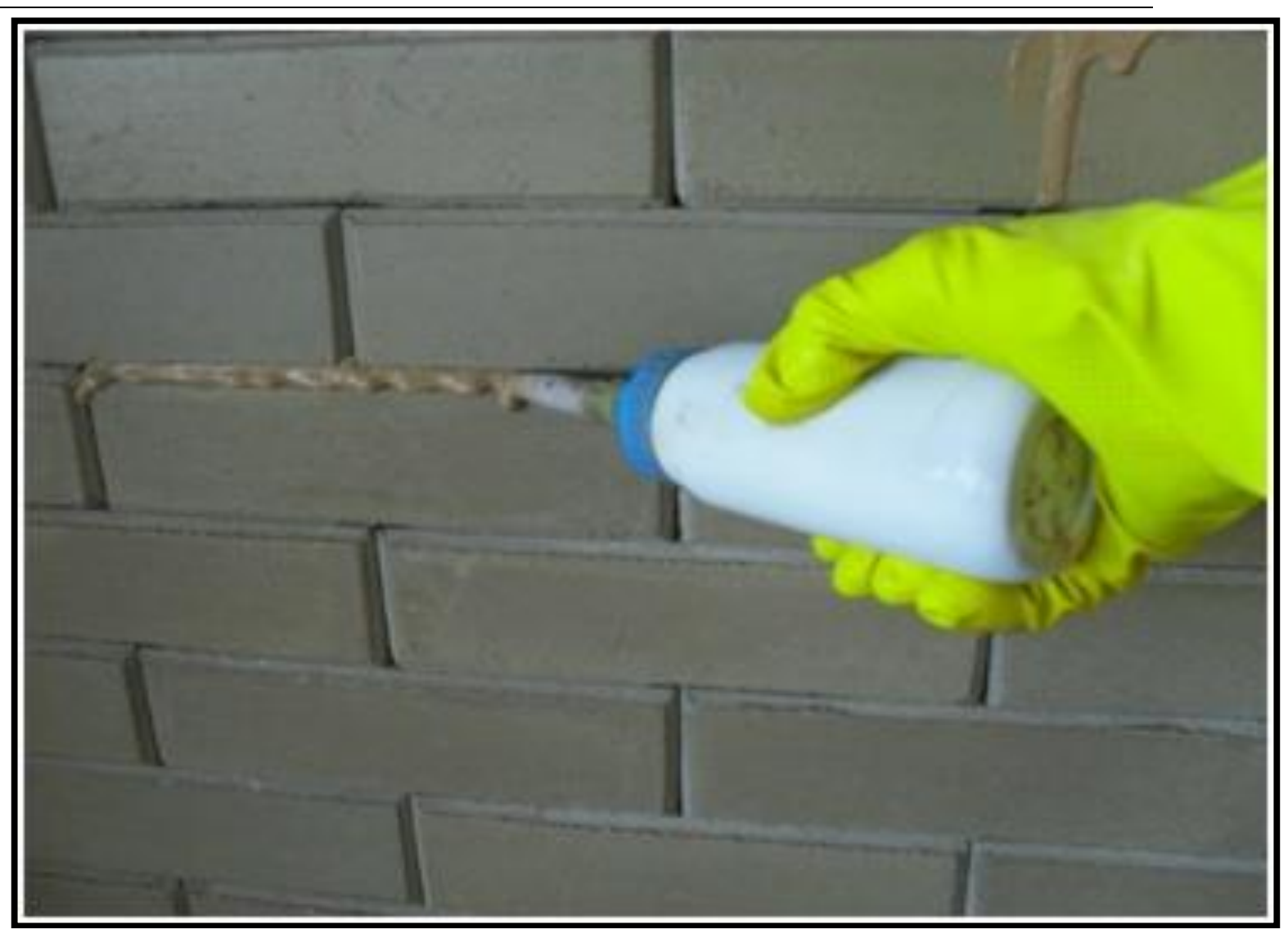

Ignis | Caçador | v.6 | n.2 | p. 18-34 | maio/ago. 2017 


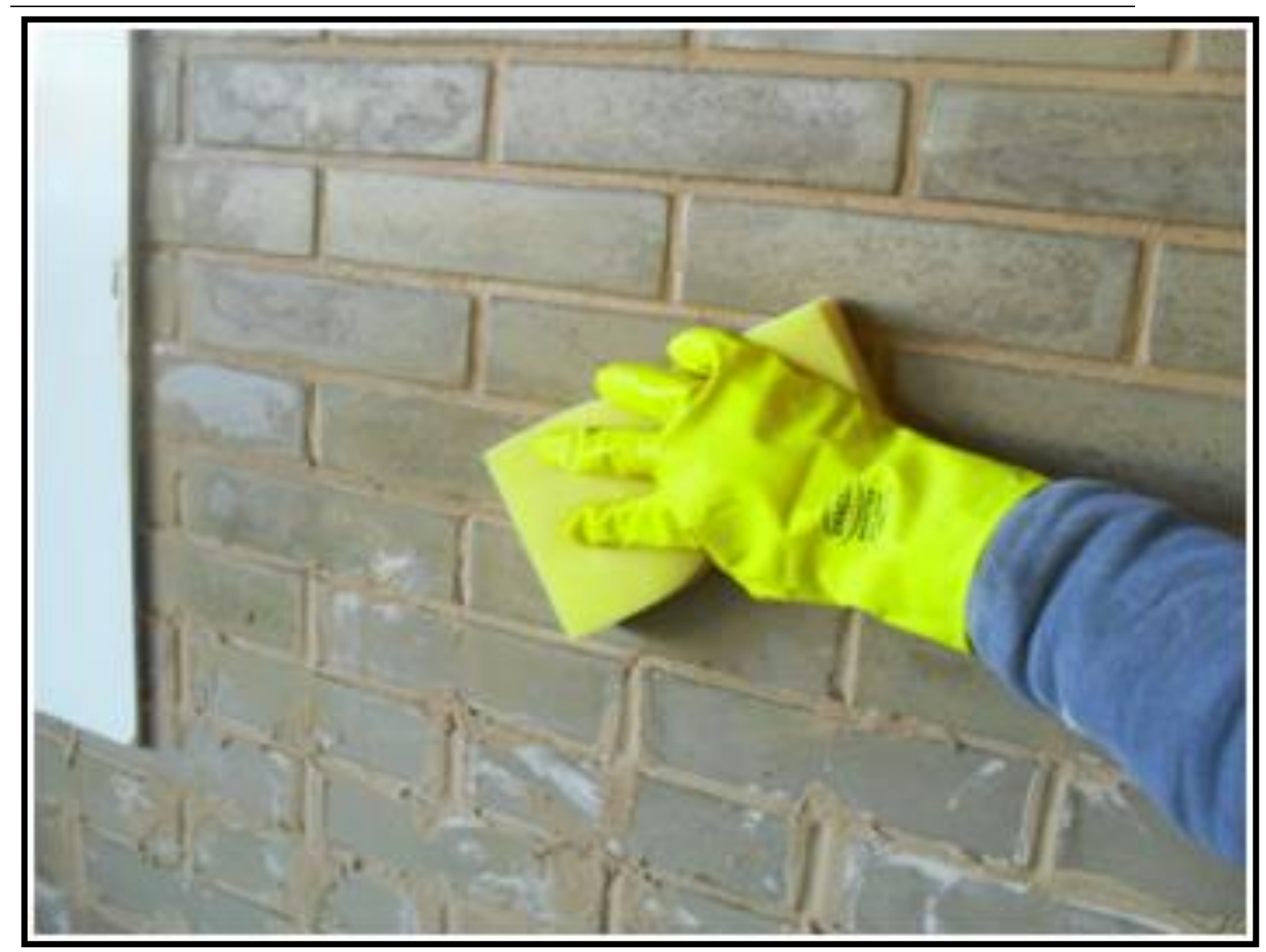

Figura 5. Aplicação de rejunte

Fonte: Intijol. (2015)

\section{CONFORTO DEVIDO ÁS CARACTERISTICAS}

Tendo em vista a composição base dos tijolos ecológicos de adobe e solocimento, pode-se dizer que são excelentes materiais quando se fala de conforto em ambientes. A principal característica do solo na utilização do mesmo como alvenaria, é a resistência térmica pelo fato da argila possuir baixo coeficiente de condutibilidade térmica, cerca de $\lambda=0,72$. (letra grega lâmbda que exprime a quantidade de calor (Watts) que passa por um corpo de determinada espessura (metros) perante uma diferença de temperatura (Celsius))

Quando misturado com o cimento Portland o solo utilizado na composição do solo-cimento acaba diminuindo seu coeficiente de condutibilidade térmica proporcionalmente, sabendo que o coeficiente de condutibilidade térmica do 
cimento é de $\lambda=0,29$. Considerando que o tijolo solo-cimento normatizado possui vazados internos que quando utilizados em alvenarias formam galerias de ar ao longo das paredes, o que diminui ainda mais sua capacidade de condução, pois o coeficiente de condutibilidade térmica do ar é de $\lambda=0,026,0,004 \mathrm{w} / \mathrm{m}^{\circ} \mathrm{C}$ a menos que a fibra de vidro utilizada em isolamentos térmicos de equipamentos específicos de alta temperatura.

\section{CUSTO FINAL}

Levando em consideração que a quantidade de tijolos solo-cimento para execução de um metro quadrado de parede é de 55 peças, enquanto um tijolo cerâmico comum é 37 , de primeiro momento torna-se inviável a utilização do mesmo como alvenaria de vedação. Em contrapartida, um orçamento completo de execução de obra pode vir a mostrar a verdadeira economia do tijolo ecológico, que se dá no processo de utilização do mesmo, tempo de execução, praticidade, economia de materiais, eficiência energética, dentre outras inúmeras vantagens. Esta economia pode ser de $30 \%$ a $50 \%$ do valor total de uma obra de alvenaria com tijolos cerâmicos, valor este que varia de acordo com o acabamento determinado pelo proprietário.

\section{BENEFÍCIOS DO TIJOLO ECOLÓGICO}

Conforme Santana et al., (2013) ao analisarmos a quantidade de tijolos necessários para a construção de uma área de $60 \mathrm{~m}^{2}$, estima-se 1500 unidades para o tijolo convencional e 3420 de tijolos ecológicos. É importante salientar que a cada1000 tijolos ecológicos o equivalente a $2,5 \mathrm{~m}^{3}$ de entulhos da construção civil que acabam sendo reincorporados no processo produtivo, para a fabricação de tijolos, o que equivale a $150 \mathrm{~m}^{3}$ retirados de entulhos ao mês.

Com base em estudos como este é possível afirmar que a utilização de resíduos sólidos da construção civil como agregado na composição do solo-cimento é eficaz quando se fala em sustentabilidade, pois evita a destinação incorreta dos resíduos e reintegra-os ao processo produtivo. O tijolo ecológico é o mais completo quando se fala em benefícios, pois possibilita a redução do tempo de construção em $30 \%$ em relação à alvenaria convencional, distribuem melhor a carga de peso sobre as paredes devido aos seus encaixes e colunas embutidas nos próprios furos, reduz 
o consumo de madeiras para formas nas construções, proporciona uma economia de concreto e argamassa em cerca de $70 \%$ e de aço $50 \%$ em relação à estrutura de concreto armado (MOTTA et al., 2014).

Constata-se que há uma economia financeira na conclusão da obra devido ao tempo de execução reduzido através de um processo construtivo diferenciado que proporciona rigidez e segurança resultantes de um encaixe perfeito entre um tijolo e outro. Segundo Motta et al., (2014) o fator determinante para uma melhor qualidade do solo-cimento depende do tipo de solo, umidade de moldagem, tipo de prensa, proporção de solo/cimento, tipo de estabilizante e o processo de cura. Para uma maior resistência à compressão, absorção e durabilidade do solo-cimento, deve-se utilizar um percentual maior de cimento na mistura.

De acordo com Santana, Carvalho e Faria (2013) a fabricação do tijolo ecológico de resíduos da construção civil auxilia a qualidade ambiental, devido à reciclagem. Conforme Morais, Chaves e Jones (2014) o tijolo ecológico é viável tecnicamente devido sua grande durabilidade e manutenção reduzida nas edificações com sua confecção.

\section{CONCLUSÃO}

Com base nas pesquisas realizadas para o desenvolvimento deste trabalho, o qual teve como objetivo a análise da eficiência do tijolo ecológico na construção civil, mostra-se as seguintes conclusões:

Analisaram-se as vantagens e desvantagens do tijolo, confirmando-se que o mesmo oferece benefícios financeiros em uma construção onde é aplicado, por possibilitar a utilização de técnica construtiva diferenciada da convencional resultando na economia de materiais, tempo de execução e mão de obra, o que pode ser uma das melhores opções em projetos sociais que buscam a agilidade de construção de moradias para acomodar famílias de baixo poder aquisitivo.

O tijolo ecológico é um contribuinte ao bom funcionamento do ecossistema por ser resultado de um processo de fabricação limpo que aproveita matéria prima em abundância no planeta, o solo, e em alguns casos os resíduos da própria construção civil, conseguindo assim proporcionar sustentabilidade para quem adota a utilização do mesmo. 
Em contrapartida, o tijolo reciclado perde para o tijolo cerâmico em alguns quesitos como: peso próprio, sendo até $50 \%$ mais pesado em relação ao tijolo cerâmico; limitação de tamanho de projeto, podendo ser utilizado em projetos de pequeno e médio porte enquanto que o cerâmico não possui limitações, desde que utilizado como alvenaria convencional de revestimento sem função estrutural;

Pode- se afirmar que o tijolo de ecológico possui o baixo consumo de energia para sua confecção e possibilidade de fabricação in loco, permitindo a execução de uma gama de traços arquitetônicos, pela possibilidade de moldar o tijolo no formato necessário sem perder qualidade, dependendo do projeto e das necessidades.

\section{REFERÊNCIAS}

BRAGA, B.; HESPANHOL, I.; CONEJO, J.G.L.; MIERZWA, J.C.; BARROS, M.T.L.; SPENCER, M.; PORTO, M.; NUCCI, N.; JULIANO, N.; EIGER, S. Introdução à engenharia ambiental: $O$ desafio do desenvolvimento sustentável. 2 ed. São Paulo: Pearson Prentice Hall. 2005.

COELHO, P.E.; CHAVES A.P. Reciclagem de entulho - Uma opção de negócio potencialmente lucrativa e ambientalmente simpática. Areia e Brita, São Paulo, v. 2, n. 5, p. 31-35, 1998.

GODOI, B.C.S. Requisitos de sustentabilidade para o desenvolvimento de projetos residenciais multifamiliares em São Paulo. Dissertação (Mestrado). FAUUSP:São Paulo. 2012.

MORAIS, M.B.; CHAVES, A.M.; JONAS, K.M. Análise da viabilidade de aplicação do tijolo ecológico na construção civil contemporânea. Revista Pensar Engenharia, v.2, n. 2, p.1-12, julho, 2014.

MOTTA, J.C.S.S.; MORAIS, P.W.P.; ROCHA, G.N.; TAVARES, J.C.T.; GONÇALVES, G.C.; CHAGAS, M.A.; MAGESTE, J.L.; LUCAS, T.P.B. Tijolo de solo-cimento: Análise das características físicas e viabilidade econômica das técnicas construtivas sustentáveis, e-xacta, Belo Horizonte, v.7, n.1, p. 13-26. 2014.

SANTANA, J.E.S.; CARVALHO, A.C.X.; FARIAS, R.A.P.G. Tijolo ecológico versus tijolo comum: Benefícios ambientais e economia da energia durante o processo de queima. In: IV Congresso Brasileiro de Gestão Ambiental. 2013. 
SANTOS, W.P.C.; SUZART, V.P.; SILVA-JUNIOR, N.F.S. Tendência tecnológica para o processo de preparação de compósito à base de solo-cimento e fibra de bananeira para fabricação de tijolos e tecnologias correlatas através da pesquisa em documentos de patentes. Cadernos de Prospecção, v.6, n.1, p.36-44. 2013.

YEMAL, J.A. ; TEIXEIRA, N.O.; NÃ̃̃S, I.A. Sustentabilidade na Construção Civil. In: 3rd International Workshop Advances in Cleaner Production. 2011. 